\title{
La interacción entre la posición sintáctica y el significado procedimental en el uso de digo
}

\author{
Verónica Böhm ${ }^{1}$ \\ Universidad de Potsdam, Alemania \\ Anja Hennemann ${ }^{2}$ \\ Universidad de Potsdam, Alemania
}

\begin{abstract}
Resumen
Por lo general, digo se comporta como un marcador discursivo, por medio del cual se ordenan y estructuran procesos cognitivos del hablante para interpretar y comprender un texto o un enunciado, marcando textualmente la actitud del hablante o del autor de la información. El presente estudio tiene como objetivo analizar de manera cualitativa la posición sintáctica de digo en el sintagma oracional, así como sus diversos significados o funciones semánticopragmáticas que se derivan de ella en el enunciado. En este sentido, también tendremos en cuenta los elementos contextuales con que suele aparecer digo, para luego intentar establecer una relación entre su posición sintáctica y su significado procedimental en el enunciado. Los ejemplos del corpus serán tomados del Corpus de la Real Academia Española (CREA) y del Corpus del Español (CdE).
\end{abstract}

\footnotetext{
1 Para correspondencia, dirigirse a: Verónica Böhm (juboehm@uni-potsdam.de), Universidad de Potsdam, Am Neuen Palais 10, 14469 Potsdam, Alemania.

2 Para correspondencia, dirigirse a: Anja Hennemann (henneman@uni-potsdam.de), Universidad de Potsdam, Am Neuen Palais 10, 14469 Potsdam, Alemania.
} 
Palabras clave: digo, marcador del discurso, significado procedimental, posición sintáctica, estudio de corpus, análisis cualitativo.

THE INTERACTION OF THE SYNTACTIC POSITION AND THE PROCEDURAL MEANING IN THE USE OF DIGO

\begin{abstract}
In general, digo ('[I] say') behaves like a discourse marker, through which cognitive processes of the speaker are ordered and structured in order to interpret and understand a text or an utterance, literally marking the attitude of the speaker or author of the information. The present study aims to qualitatively analyze the syntactic position of digo in the syntagm, as well as its various meanings or semanticpragmatic functions derived from it in the utterance. In this context, we will also take into account the contextual elements with which digo usually appears, and then try to establish a relationship between its syntactic position and its procedural meaning in the utterance. The corpus examples will be taken from the Corpus de la Real Academia Española (CREA) and the Corpus del Español (CdE).
\end{abstract}

Keywords: digo, discourse marker, procedural meaning, syntactic position, corpus study, qualitative analysis.

Recibido: $13 / 01 / 18 \quad$ Aceptado: $30 / 04 / 18$

\title{
1. INTRODUCCIÓN
}

El presente estudio tiene como objetivo analizar la posición sintáctica de digo en el sintagma oracional y su significado procedimental que se obtiene de acuerdo a su posición sintáctica y a los elementos contextuales con que aparece en el enunciado. Por ejemplo, en estos tres ejemplos, digo no expresa la misma función:

(1) Por eso digo: son licitaciones bamba, licitaciones amarradas. Muy bien, van dos. ¿Hay otra empresa? Van dos, por supuesto. Argos Trading Sociedad Anónima, esta es la tercera. Argos Trading Sociedad Anónima (CREA, Oral, Red global: enlace global con Hildebrandt, Peru). 
(2) Un mediodía, ya digo, de domingo, de padres y de perros. Blanca Marsillach se sienta en el suelo. Mi máquina de escribir, mi valentine roja está de pie en la mesa, interrumpida. Blanca ha visto un parchís y quiere jugar al parchís (CREA, El País, 01/04/1985).

(3) Pero no sé... para mí que se le está poniendo un aire distinto y distante, tipo calvosoteliano. La alegría de la huerta, digo (CREA, El Mundo, 08/08/1996).

Mientras que en el ejemplo (1) digo aparece al inicio de la oración, introduciendo una información de la cual el hablante parece estar seguro, en el ejemplo (2), digo aparece insertado en función parentética. En el ejemplo (3) digo aparece al final de la oración y marca la actitud pragmática del hablante, que expresa su enunciado cortésmente.

Los (muy pocos) estudios realizados sobre digo, hasta ahora, muestran que digo se comporta como un marcador discursivo (cf. Fuentes 2004: 138) o como una marca intensificadora o enfatizadora de alto grado de acierto formulativo, por medio del cual "el hablante señala al interlocutor su apreciación del grado de acierto de la secuencia que está produciendo" (Díaz y Labarca 2010: 12; cf. también Fant 2005, 2006; Sorensen 1999; Meyer-Hermann 1988).

Además de las funciones pragmático-discursivas de digo analizadas por los autores anteriormente mencionados, defendemos la tesis de que digo, dependiendo de su posición sintáctica y de los elementos proposicionales que le acompañan en un enunciado, puede asumir otras funciones relacionadas con la actitud epistémica y cognitiva del hablante, así como su actitud (pragmática) frente a su interlocutor.

También será importante analizar si el uso de digo en combinación con el pronombre yo -ya sea antepuesto (yo digo) o pospuesto (digo yo) - refuerza o debilita la función de marcador discursivo de digo, o si permite otras funciones semánticas de digo. Compárese el siguiente ejemplo de digo con el pronombre personal yo, a diferencia de los ejemplos anteriores (1-3):

(4) Bueno, pues muchas gracias, Joaquín, por ese ese matiz. Digo yo digo yo que será así. Sí, sí yo creo que sí; sigue sigue con el tema (CREA, Oral, Radio, Madrid, 21/10/91, España).

En este estudio analizaremos las diversas posiciones sintácticas en que suele aparecer [yo] digo [yo] (al inicio, a la mitad y al final de la oración) y su interacción semántica con elementos contextuales que contribuyen con su significado procedimental, discursivo y pragmático. Los ejemplos para el análisis cualitativo han sido tomados del CREA y del CdE (Web/ Dialects). 


\section{DIGO COMO MARCADOR DISCURSIVO. ESTADO ACTUAL DE LA INVESTIGACIÓN}

De acuerdo con la definición de Martín Zorraquino y Portolés (1999: 4055): "La denominación de 'marcadores del discurso' se atribuye a ciertas unidades lingüísticas que puedan presentar usos discursivos, empleos enfatizadores, valores expresivos, etc.". Justamente, este es el empleo o uso enfatizador que caracteriza a digo. Según Sorensen (1999) y Meyer-Hermann (1988), digo -como marca enfatizadora-realza la veracidad o importancia de lo que se está diciendo (cf. también Díaz y Labarca 2010: 15), como lo muestra el siguiente ejemplo de yo digo que:

(5) Por lo tanto, si bien el doctor Orsi fue un destacado jurista e historiador, yo digo que por sobre todas las cosas fue un modelo de vida, un hombre que se comprometió desde muy pequeño (CREA, Oral, Reunión 2, 1-3 de marzo de 1999, Argentina).

Según el análisis realizado por Fant (2006) sobre la base de un corpus que contenía cuatro conversaciones grabadas en la Pontificia Universidad Católica de Chile y dos conversaciones en la Universidad Nacional de La Plata, Argentina, se le atribuyó a digo la función de marcador preformulativo del verbo decir con efecto prospectivo, es decir, introduciendo una información:

(6) Yo digo, señor presidente, que el programa propuesto por la Alianza para superar esa supuesta amenaza es muy difuso e insustancial (CREA, Oral, Reunión 47, 16 de septiembre de 1998, Argentina)³.

Entiéndase como 'marcadores preformulativos' aquellos marcadores discursivos que "modalizan [una proposición] en sentido unidireccional prospectivo" (Fant 2006: 12), es decir, que atribuyen a la secuencia "de derecha" un cierto valor de refuerzo o alto grado de acierto afirmativo (Fant 2006: 14), tal y como lo hemos visto en el ejemplo anterior (6).

Según Fant (2006: 18-19), también se encuentra la función intensificadora o enfatizadora de digo cuando va antecedida por el pronombre personal yo, el que refuerza el alto grado de acierto formulativo porque es la persona

\footnotetext{
3 Los ejemplos son propios de las autoras de esta contribución, ya que Fant (2006) no proporciona ningún ejemplo al respecto.
} 
misma que tiene el peso autoritario de un yo para decir algo. Obsérvese el siguiente ejemplo que puede ilustrar la explicación de Fant:

(7) Uno aprendía a leer y escribir nada más, raro el que seguía una carrera. Por eso digo yo, ha cambiado mucho todo ahora (CREA, GIA, Testimonios varios, 1986, Chile).

Sobre la base de un Corpus Sociolingüistico de Mérida (Venezuela) de Domínguez y Mora (1995), Díaz y Labarca (2010: 15-17) analizaron el uso de digo como un marcador de intensificación y enfatización, llegando a la conclusión de que por medio de digo el hablante asume el valor de certeza de su enunciado, sobre todo, cuando digo aparece con el pronombre yo, que refuerza el compromiso del hablante sobre lo que dice:

(8) Hab.: Sí, lógico, entonces no se acuerda, pero... bastantes amistades, yo te digo, la mejor amistades de... mías que he tenido es... ha sido en el mercado, en los mercados ive? y por eso es que yo digo que... sinceramente, me muero en un mercado ([MDB4MA], (Díaz y Labarca 2010: 15).

En su análisis sobre digo, Díaz y Labarca (2010) no solo confirmaron la hipótesis de Fant (2006), sino también se refirieron al uso de digo al inicio y final de oración. Según su análisis, digo actúa como modalización de confiabilidad $^{4}$ que de acuerdo a su posición sintáctica "el valor de certeza del enunciado varía" (Díaz y Labarca 2010: 5). Así, en función sintáctica retrospectiva, o sea, al final de la oración, digo (yo) indica que toda la proposición enunciada es solo "una opinión del hablante, no hay total certeza, carece del énfasis de acierto y propiedad que tiene la otra posibilidad ya evaluada" (Díaz y Labarca 2010: 16):

(9) Hab.: ... ya no hacen esas fiestas, que hacían antes ¿ve? Bastantes fiestas hacían, por lo menos en una cuadra siempre se veían muchas paradas de niño, ahora ya no, ahora ya es distinto, pero también debe ser por la situación que hay, que ... más bien ... que ya dejó de... se dejó de esas fiestas, será, digo yo (Díaz y Labarca 2010: 16).

En posición prospectiva, (yo) digo intensifica la certeza del enunciado: 
(10) Hab.... y pero si vamos a empezar que voy a echar para atrás, vamos a ser como el cangrejo, todo para atrás y nunca para adelante... ¿ve? Y entonces pues... todo el mundo debe pensar que... las cosas hay que pensarlas positivamente, pero claro, lógico, también yo digo, también sentarse a analizar y dialogar (Díaz y Labarca 2010: 17).

Díaz y Labarca (2010: 5) también pudieron comprobar el uso de yo digo precedido por otros marcadores discursivos, como bueno, entonces, pues, como o por una conjunción causal, tal y como lo veremos más adelante. Por ahora, baste este ejemplo para ilustrar la explicación:

(11) Hab.: o todo mundo quiere decir "no, yo no voy a trabajar a allá a la tierra porque... no me gusta, que es muy forzado", pues yo digo que tampoco es así porque entonces hay que... pensar... tener un pedacito de terreno para uno ir a sembrar un po... una papita o alguna cosa y... (Díaz y Labarca 2010: 5).

\section{LA NOCIÓN DEL SIGNIFICADO PROCEDIMENTAL}

$\mathrm{Al}$ trabajar con la noción del 'significado procedimental' deberá resaltarse que este se usa en la lingüística, por lo menos, con dos significados: en un sentido canónico y uno no canónico.

Las unidades 'reales' procedimentales son tratadas, con frecuencia, en un marco teórico de la relevancia (cf., por ejemplo, Blakemore 1987, 2004; Carston 2002). Desde el punto de vista teórico de la relevancia, las unidades procedimentales (por ejemplo, los determinantes, como el artículo el o los marcadores discursivos, como pero) codifican instrucciones que restringen la fase inferencial de comprensión y motivan tanto las explicaturas como las implicaturas, por lo que las unidades procedimentales guían los procesos interpretativos:

procedural items (e.g. determiners such as 'the' or discourse markers such as 'but') encode instructions that constrain the inferential phase of comprehension, and are involved in the derivation of both explicatures and implicatures. Thus procedural items guide interpretive processes, such as the pragmatic enrichment of semantically underspecified terms [...]. (Bezuidenhout 2004: 125-126; cf. también Carston 2002: 379). 
El estudio de Blakemore (2004) sobre los marcadores discursivos muestra un análisis muy exhaustivo de los conectores discursivos, como but y however. Según Blakemore, la teoría procedimental "deals with the way in which elements of linguistic structure map directly onto computations" (1987: 144). De este modo, los conectores son elementos que restringen la fase inferencial de la comprensión. Blakemore explica la noción del significado procedimental al destacar el límite distintivo entre el significado conceptual y el procedimental. El primero -el significado conceptualcontribuye conceptos a la forma lógica de una oración, es decir, influye en la representación semántica. En otras palabras, "“...] in conceptual encoding, linguistic forms encode conceptual information" (Huang 2007: 197). Por otro lado, en la noción del significado procedimental un hablante puede darle un sentido a dos expresiones y decir si ambas expresiones pueden codificar el mismo concepto sin tener que comprobarlo, o si cada expresión puede ser sustituida por la otra en todos los contextos. Entonces, la noción del significado procedimental puede definirse de la siguiente manera:

$[\ldots]$ even when the definition of a concept proves controversial, there is a sense in which each speaker can bring it to consciousness and say whether two expressions encode the same concept without having to actually test whether they can be substituted for each other in all contexts. As anyone who has tried to analyse them will know, the situation is very different with expressions such as but and utterance initial well. Ask a native speaker what these mean, and you are much more likely to receive a description or illustration of their use than a straightforward paraphrase. Moreover, native speakers are unable to judge whether two of these expressions - say, but and however - are synonymous without testing their inter-substitutability in all contexts (Blakemore 2004: 82-83; cf. también Wilson y Sperber 1993: 16).

Por mencionar otro ejemplo, se dice que el modo tiene un significado procedimental (canónico): Sperber y Wilson ( ${ }^{2} 1995$ [1986], 1998) le asignan a los indicadores del modo este significado procedimental porque restringen la inferencia pragmática que debería proceder en el destinatario con respecto a la actitud intencionada en la proposición que es expresada por medio del indicador del modo:

[...] illocutionary-force indicators such as declarative or imperative mood or interrogative word order merely have to make manifest a rather abstract property of the speaker's informative intention: the direction in which the relevance of the utterance is to be sought (Sperber y Wilson ${ }^{2} 1995$ [1986]: 254). 
Entonces, el modo y los conectores discursivos son ejemplos de elementos que tienen un significado procedimental que se caracteriza por el hecho de que no contribuye con ningún concepto, sino más bien proporciona una restricción o indica cómo deberían proceder ciertos aspectos de inferencia pragmática, es decir, indica específicos procesos computacionales. En palabras propias de Huang (2007: 197), el significado procedimental "does not contribute any concept but rather provides a constraint on, or indication of the way in which certain aspects of pragmatic inference should proceed, that is to say, it indicates particular computational processes". Los procesos computacionales deberán entenderse como la aplicación de reglas e inferencias gramaticales, etc. (cf. Wilson y Sperber 1993: 16). Martín Zorraquino y Portolés (1999: 4071) también describen el 'significado procedimental' como "una serie de instrucciones semánticas que guían las inferencias que se han de efectuar de los distintos miembros del discurso en los que aparecen estas unidades". Por lo general, los marcadores discursivos contienen un significado procedimental, mas no referencial, conceptual o representacional ${ }^{5}$, puesto que codifican y procesan ciertas inferencias que llevan a la interpretación textual del enunciado en que aparecen, o como lo dice Portolés (1998: 22): "[los marcadores del discurso] no contribuyen al significado conceptual de las intervenciones, ni a sus condiciones de verdad, pero sí a su procesamiento, esto es, a la realización de unas inferencias determinadas a partir de la relación de lo dicho y el contexto".

Digo y sus variantes no son, en realidad, marcadores discursivos típicos o canónicos, en comparación, por ejemplo, con pues, vamos or o sea. En este sentido, al tratar con un marcador discursivo no canónico, parece interesante considerar la noción de un significado procedimental no canónico. Al estudiar los adverbios/ locuciones adverbiales en las lenguas románicas y en inglés, Haßler (2010), Cornillie (2010) y Simon-Vandenbergen y Aijmer (2007) han trabajado de alguna manera con el uso 'no canónico' de lo 'procedimental', porque las expresiones que analizan no son tratadas como algo que tiene exclusivamente significado procedimental. Estos autores explican más bien que ciertos adverbios o locuciones adverbiales son procedimentales en su naturaleza -además de codificar un significado conceptual- porque codifican información sobre "how utterances containing these expressions should be processed" (Ifantidou 2001: 87). Por lo tanto, los destinatarios se encuentran obligados a inferir pragmáticamente la correcta interpretación,

\footnotetext{
5 Entiéndase como 'significado referencial, conceptual o representacional' "lo que tienen las palabras como mar, vender o despacio, [...] es decir, [...] nos dicen cosas" (Nogueira 2010: $7)$.
} 
usando suposiciones contextuales y principios generales de comunicación (cf. Ifantidou 2001: 59). De este modo, ambos significados -el conceptual y el procedimental- no deberán excluir el uno del otro; se asume incluso la coexistencia de ambos significados para ciertos elementos lingüísticos (cf. también Cappelli 2007: 25). Aplicaremos esta explicación a este estudio y analizaremos el significado de digo, yo digo, digo yo y yo te digo en relación con su posición sintáctica. Es decir, analizaremos cómo el perfil semántico permite los significados procedimentales: "how the semantic profile allows for procedural meanings" (Cornillie 2010: 303). Entonces, el uso 'no canónico' de lo procedimental tratado aquí se refiere a la noción del significado procedimental que puede ser combinado con el significado conceptual, lo que puede ser asignado a digo y sus variantes, pues serán, hasta un cierto punto, procedimental mientras señalen o indiquen cómo deberá procesarse pragmáticamente el contenido proposicional.

\section{EL SIGNIFICADO PROCEDIMENTAL DE DIGO DE ACUERDO A SU POSICIÓN SINTÁCTICA}

Tal y como lo hemos visto anteriormente, algunos autores, como Sorensen (1999), Meyer-Hermann (1988), Díaz y Labarca (2010: 15) y Fant (2006), le atribuyen a digo la función de marcador discursivo, de tipo preformulativo, de intensificación y enfatización cuando introduce, en posición prospectiva, un enunciado: yo digo (que), y refuerza el valor de verdad del enunciado ${ }^{6}$. Cuando digo (yo) aparece en posición retrospectiva, es decir, al final del enunciado, este marcador atenúa el valor de verdad. Lo interesante de estos estudios es el uso de digo con el pronombre personal yo que refuerza el alto grado de certeza que tiene el hablante sobre lo que dice, como lo muestran nuestros ejemplos tomados del CREA:

(12) Entonces, para la construcción, para el mobiliario, para estuchería, etcétera, etcétera, y yo digo que, en general, cualquier digamos, cualquier mueble o cualquier cosa que no deba de ser de madera (CREA, Oral, Televisión, Madrid, 05/07/91).

6 Sobre otras funciones del marcador discursivo digo, cf. Fernández (2002). 
(13) Y digo yo que por qué no compramos el pescado en la pescadería, como todo el mundo y a una hora decente.

- ¡Anda vas comparar...! (CREA, El Mundo, 23/08/1996).

Aunque en el primer ejemplo (12) el pronombre yo aparece antepuesto a digo (yo digo) y en el segundo ejemplo (13) después de digo (digo yo), el hablante se refiere a él mismo como el autor de tal información. Es obvio, por lo tanto, que el valor de certeza del enunciado sea muy alto, ya que es el mismo hablante -y no otro- el autor de tal información. En este caso, digo yo asume también una función deíctica y evidencial.

En nuestro estudio cualitativo hemos tratado de analizar todos los casos posibles de [yo] digo [yo] de acuerdo a su posición sintáctica (al inicio, a la mitad o al final del enunciado). Asimismo, hemos tomado en cuenta los elementos gramaticales, léxicos y sintácticos con los que suele aparecer digo, los mismos que pueden contribuir al significado procedimental no canónico de digo.

A diferencia de los otros estudios realizados sobre digo, con nuestro estudio pretendemos enfocarnos en los significados procedimentales no canónicos de digo relacionados con su función no solo a nivel discursivo y pragmático, sino también a nivel de la subjetividad del hablante en cuanto al uso de digo/ yo digo/ digo yo para indicar implícita o explícitamente la actitud epistémica del hablante, es decir, el conocimiento que tiene el hablante respecto a una situación. Es evidente que el uso de digo implica desde ya que el autor de la información expresada es el mismo hablante que emite su enunciado. No obstante, observaremos casos en los que por medio de digo y en todas sus variantes el hablante no asume completamente la responsabilidad de lo que dice, expresando así incertidumbre e inseguridad sobre su enunciado. Asimismo, se analizará el uso de digo en relación con la presencia o no del pronombre yo, ya sea que este vaya antepuesto (yo digo) o pospuesto (digo yo). Desde el punto de vista sintáctico, se observará si digo puede actuar como una partícula cognitiva, por medio del cual no es necesario que el hablante utilice digo en sus enunciados orales.

\subsection{El CASO DE DIGO AL INICIO DEL ENUNCIADO}

En los ejemplos analizados del CREA y del CdE, digo aparece en posición sintáctica prospectiva, es decir, introduciendo una proposición. El marcador discursivo digo aparece en la mayoría de los casos con el pronombre yo antepuesto (14) y en combinación con otros marcadores discursivos, como de hecho (15) y entonces (16), así como con la conjunción y (17): 
(14) Yo digo, si uno no tiene un nombre feo ni difícil ni muy largo... ¿por qué semejante crimen a la identidad personal? (CdE, blogs.lanacion. com.ar).

(15) De hecho, yo digo que nosotros fabricamos muebles, lo que luego ponen en su interior, realmente a ahí sí me lleva sin cuidado, ¿no? (CREA, Oral, Madrid, 05/07/91, España).

(16) Poner: Ver apartado primero. Entonces, yo digo lo había preparado para no volver a repetir operaciones, ¿no?, que aunque nos den puntos, al restar nos salen los vectores a y be que habíamos puesto antes. Y entonces, si vemos el apartado primero, este resultado nos había salido, el vector asociado: menos cuatro, siete, cinco, ¿conformes? Bueno, necesito el módulo. (CREA, Oral, Madrid, 19/12/91, España).

(17) Y no sé, si se ha roto la Rusia podría romperse China y Cuba también está ahí, y te como a esos países tenéis muchos, ¿no? Sí. Y yo digo, por otra parte, yo pienso que derechas e izquierdas ha habido siempre, ahora mismo hay, y yo creo que habrá siempre (CREA, Oral, Madrid, 14/01/92, España).

Si bien, en los ejemplos anteriores (14-17) yo digo refuerza el valor de verdad de la proposición, se puede observar también que el uso de yo digo indica la actitud del hablante sobre lo que piensa y cree de la situación expresada. Esto se puede observar muy claramente en el ejemplo (17) cuando el hablante dice secuencialmente: yo digo, por otra parte, yo pienso [...], y yo creo [...]. Esto indica que el uso de yo digo, además de asumir la función de un marcador discursivo preformulativo que enfatiza la certeza del hablante sobre lo que dice, marca su actitud cognitiva y epistémica, es decir, su creencia o pensamiento de lo que dice.

En los siguientes ejemplos (18-19), el hablante expresa su opinión con respecto a una situación determinada. Nótese que digo aparece sin el pronombre $y o$, siendo introducido entre comas por el marcador consecutivo por ello (18) y, sin coma, con por eso (19). En ambos casos, el hablante expresa una consecuencia o conclusión de lo que se ha venido diciendo anteriormente:

(18) Por ello, digo, este debate no se lo merecen los trabajadores, quienes tampoco se merecen este proyecto. Por eso, voto a favor del empleo, voto a favor de la pequeña y mediana empresas. Y como este proyecto los amenaza seriamente, no puedo aprobar el informe de la Comisión Mixta (CREA, Oral, Sesión 17, 01/12/1999, Chile).

(19) Por eso digo, ya estamos semiindustrializados y ¿cómo lo hicimos?: a poncho y con lo que quedaba. El proceso iniciado en 2003 fue 
una construcción social -yo lo defino así- con diferentes actores económicos y sociales (CdE, iade.org.ar).

Es importante mencionar que a pesar de que digo aparezca al inicio de la proposición antecedido por los marcadores discursivos respectivos ( $p o r$ ello y por eso) su función discursiva es reformulativa conclusiva, es decir, tiene efecto retrospectivo, pero al mismo tiempo también es prospectivo: El hablante reformula lo anteriormente dicho y concluye con su mera opinión al respecto. Esta interpretación semántica se pierde un poco al usar digo con el pronombre yo antepuesto (yo digo), ya que el foco discursivo de la proposición es yo, el autor de tal información. Compárense los ejemplos anteriores (15) y (16) de yo digo con marcadores discursivos similares de hecho y entonces respectivamente. Lo mismo parece ocurrir con digo más el pronombre yo pospuesto (digo yo), por medio del cual se indica que la fuente o el autor de tal información es el mismo hablante que expresa su opinión al respecto, sobre todo, cuando va antecedido por la conjunción $y$ :

(20) Forza Milan y a ganar hoy!! Y digo yo, con un delantero que fichemos, solo un fichaje de repente nuestras cabezas $[\ldots](\mathrm{CdE}$, milanadictos. com).

(21) Y digo yo, si me tomo unas vacaciones para desconectar, aprovecharé para decirle a la realidad que me espere sentada, que ya volveré, que me gusta esto de soñar como tu cuerpo se adueña del mío (CdE, blogs. laverdad.es).

Cabe mencionar que la lectura de marcador discursivo de $y$ digo yo se obtiene cuando esta construcción es separada por medio de una coma de la proposición a modalizar, no siendo así cuando y digo yo que introduce el enunciado:

(22) Y digo yo que dudo de la realidad de esta historia porque si murieron los dos allí mismo, ¿quién ha sido el transmisor de la conversación? ¿Quién oyó la pregunta y la imaginativa respuesta? Lo dicho, aún como leyenda es bonita esta historia (CdE, custoria.blogspot.com).

En el ejemplo anterior (22), el hablante se refiere a algo que ha dicho anteriormente (su duda sobre la realidad de una historia), por lo que trata de explicar con un respectivo argumento (porque si murieron ...). Lo mismo parece ocurrir con los siguientes enunciados, donde y digo yo, en forma coordinada, es parte del enunciado en que aparece, y por medio del cual el hablante vuelve a mencionar lo anteriormente dicho: 
(23) $[\ldots]$ (mi barco es un velero grande con su palo y todo) y digo yo cuanto hay que añadir a la compra (CdE, informatica-hoy.com.ar).

(24) $[\ldots]$ hace como 100 años se murieron quemadas en una fábrica un pocotón de mujeres y digo yo que eso no es como para estar celebrándolo, y que si vamos [...] (CdE, panfletonegro.com).

Un caso particular también lo muestra yo digo en combinación con el pronombre personal te antepuesto a digo, donde pero yo te digo es parte del enunciado (ejemplo 25) y aunque, yo te digo, separado entre comas (ejemplo 26) modifica y modaliza el enunciado que aparece a su derecha. En el segundo caso, yo te digo, marca discursivamente la reafirmación del hablante sobre lo que dice:

(25) Pero yo te digo por el caso mío. Yo tengo dos años haciendo las hallacas en mi casa, y la las primeras me salieron horribles, y todas dobladas (CREA, CSHC-87 ENTREVISTA 76, Venezuela).

(26) Entre las americanas tenía pocas amigas, pero por lo menos dos o tres buenas amigas y con las que más podía contar para cualquier cosa, sí, eran las latinas. Aunque, yo te digo, trataba de relacionarme sin o sea, sin muchos prejuicios, ¿no? (CREA, CSHC-87 Entrevista 27, Venezuela).

Parece ser, entonces, que las comas también desempeñan un papel muy importante en el significado procedimental de digo, yo digo, digo yo, en posición prospectiva, o sea, al inicio del enunciado.

\subsection{El CASO DE DIGO A LA MITAD DEL ENUNCIADO}

En todos los casos analizados, digo aparece, entre comas, insertado en medio del enunciado en posición parentética:

(27) [...] sí sobre los fundamentos eternos del bien común; la justicia, digo, no puede ver sin horror un atentado tan manifiesto contra los más sagrados derechos $[\ldots]$ (CdE, adhilac.com.ar).

(28) Es un criterio bastante pobre, digo, decir que la cantidad de entrevistas que da un artista determinan su decadencia o [...] (CdE, editorialorsai. com).

(29) Ustedes no pueden hacer obra. Los mismos estudiantes no quieren trabajar, es el problema mayor que tenemos, que los estudiantes no quieren ir a clase precisamente porque, digo, es un curso que son cursos 
que exigen mayor espacio físico que los otros $\mathrm{Y}$ no lo tienen (CREA, PR-2. Hombre de 31 años, Puerto Rico).

También se encontraron casos en los que digo aparece con el pronombre personal yo pospuesto digo yo y entre comas:

(30) Una persona que trata de venderte publicidad, que es una cosa abstracta, que es una cosa realmente difícil de vender, es como, digo yo, peces de colores (CREA, Oral, BA-8, Argentina).

(31) $Y$ es una cosa que me interesa, porque eso de que haya unos trozos de mundo en donde no se pueda entrar, pues no sé, a lo mejor son una maravilla, digo yo, y No se nos permite entrar, no ¡vaya!, no sé, es que me deprime esto a mí y no Hay muchos sitios en donde no se puede entrar y no pasa nada (CREA, Oral, Tariro, tariro, 14/03/89, TVE 1).

Tanto el uso de digo y digo yo en posición parentética atenúan el valor de verdad del enunciado. Mediante el uso de digo y digo yo el hablante expresa su opinión respecto a una situación determinada, pero deja entrever que lo hace en forma incierta, es decir, no asume completamente la certeza de lo que afirma. En este caso, la función discursiva, modal-epistémica de digo y digo yo equivale a decir creo, pienso eso, pero no estoy seguro. Los siguientes ejemplos ilustran mejor el uso epistémico-modal de digo yo, porque además en todo el enunciado aparecen otros elementos que señalan la actitud modal epistémica del hablante:

(32) Creo que no estamos aprovechando no le estamos sacando la esencia a este tipo de comparecencias y valdría la pena, digo yo, reflexionar sobre esto, que las comparecencias tuvieran mayor productividad en este asunto, pero lo dejo a la Mesa Directiva y finalmente a quienes propusieron este acuerdo. Nada más. Gracias, Senador Martínez (CREA, Oral, Sesión Pública Ordinaria de la Honorable Cámara de Senadores, celebrada el jueves 3 de septiembre de, México).

(33) Pues ese día no estaba el otro médico, vino Josecito y se murió, de tan caprichosa, ¿verdad? Bueno, ésa fue mi bisabuela vasca, y a lo mejor yo habré heredado un poquitito de el tesón de esta señora vasca, digo yo, sí, porque soy constante, soy machaco, golpeo y sigo y no me desanimo y, probablemente por eso, saqué adelante ese mi proyecto y otros más, ¿verdad? [...](CREA, Oral, Encuesta 39, Mercedes Sandoval de Hempel, Paraguay).

Los ejemplos anteriores muestran que el uso de digo yo suele armonizar muy bien con elementos que marcan la inseguridad o duda del hablante 
sobre lo que dice. Casi en todos los casos analizados, aparece digo yo en un contexto modalizado, es decir, donde el hablante expresa lo que piensa, pero que a la vez no está seguro de lo que dice. En los siguientes ejemplos, la pregunta retórica ¿no? marca explícitamente la inseguridad del hablante sobre su enunciado:

(34) Todo el mundo me dice que es por los detergentes, pero no, yo pienso que es la comida. ¿La comida? Es como una alergia a la comida. Como una alergia a la comida no, hay comidas que no que caen mal, digo yo, ¿no?, porque yo a veces ni lavo, o sea, porque no lavo, yo la ropa no la lavo, siempre la mando a lavar y siempre las manos son así, a menos como siempre lavo en el cafetín, los platos y las tazas El jabón (CREA, Oral, CSMV, texto MDA5FA, Venezuela).

(35) Pues sí, entonces iban los chácharos allá dirigiendo la limpieza del cementerio sí y lo visitaban mucho, y como mi papá cuidaba el cementerio, porque él era el celador del cementerio, bueno este también lo que ocurría mucho es que los los estudiantes se iban y se robaban huesos, porque ellos no tenían con qué estudiar, digo yo, ¿no? Bastantes veces que mi papá les quitó calaveras y huesos y todo (CREA, Oral, CA-8. Mujer de 50 años. Maestra, Venezuela).

Pragmáticamente hablando, en todos los casos del uso parentético de digo y digo yo, el hablante se expresa con cierta prudencia y reserva, por lo que digo y digo yo se comportan como un marcador discursivo con función de cortesía, a lo que Quero (2014: 267) llama "positive politeness". Esta función de "positive politeness" también parece asumir digo (digo yo) cuando aparece al final del enunciado, tal y como lo veremos a continuación.

\subsection{El CASO DE DIGO AL FinAl DEL ENUNCIADO}

La posición de digo al final del enunciado no solo cierra una proposición, sino que modaliza la proposición que se encuentra a la izquierda, es decir, su efecto sintáctico es retrospectivo. En todos los ejemplos analizados, digo aparece al final del enunciado precedido por una coma:

(36) El Darín de nueve reinas no es el mismo q acá, digo. Acabo de ver la película y tampoco me gusto para nada (CdE, escribiendocine.com).

(37) $[. .$.$] un poco de coherencia en la actitud no le hace mal a nadie, digo$ (CdE, la-redo.net). 
(38) La memoria es sólo polvo. A mí me gustan los polvos, digo. Escucho una melodía conocida. Aparece por fragmentos, como una ola que [...] (CdE, falladeborde.com).

En los ejemplos anteriores (36-38), digo marca la actitud epistémica del hablante, es decir, el hablante expresa su opinión, atenuando así el contenido de su enunciado.

También en la combinación digo más el pronombre yo pospuesto (digo yo), digo yo modaliza la proposición anterior que va precedida por una coma y marca la opinión del hablante o su creencia sobre algo:

(39) Era una mujer bastante ruda en su aspecto como control, pero muy cariñosa en sus otros momentos, por supuesto. Era obligado aprender a leer y a escribir, era obligado trabajar. Como norma de ella, como matrona, pues. Pero también tenía su sus ratos donde era una mujer dulce y una cantidad de cosas, la recuerdo así. Era mi mejor abuela, digo yo (CREA, Oral, CSHC-87 Entrevista 55, Venezuela).

En los siguientes ejemplos (40-41), la opinión del hablante expresado mediante digo yo se textualiza en una línea más abajo, cuando el hablante dice lo que piensa ([...] yo pienso que $[\ldots]$ ) o expresa su incertidumbre mediante será:

(40) Sí. Mira, y eso de la introversión y la extroversión, ¿cómo es eso? No, bueno, yo. Introvertida. No, tampoco introvertida así que tú digas o sea, a mí me gusta mucho compartir con la gente y hablar, pero, o sea, que no soy una persona así que de buenas a primeras pega gritos así, salta, brinca, no, soy más bien tranquila, digo yo. No, yo pienso que es algo de mi carácter, ¿no?, soy así (CREA, Oral, CSHC-87 Entrevista 27, Venezuela).

(41) ¿ve?, bastantes fiestas hacían, por lo menos en una cuadra siempre se veían muchas paradas de niño, ahora ya no, ahora ya es distinto, pero también debe ser por la situación que hay, que más bien que ya dejó de se dejó de esas fiestas, será, digo yo (CREA, Oral, CSMV, texto MDC4FA, Venezuela).

También se encontraron casos en los que digo modaliza solo el grupo proposicional situado a su izquierda y separado por una coma:

(42) $[\ldots]$ en el mismo lugar muchos se oponen. ¡En el mismo lugar!, digo. Y después esos mismos se quejan de que [...] (CdE, lapassucci.blogspot. com). 
(43) ¿Qué tiene el peronismo de eficaz? Para la gente, digo. Para la política me importa un cuerno (CdE, periodicotribuna.com.ar).

En ambos casos -en los ejemplos (42) y (43)- digo parece asumir la función de un marcador discursivo reformulativo o correctivo, por medio del cual el hablante explica o recapitula su formulación anterior. En los siguientes ejemplos (44-45), la función correctiva de digo se hace aún más notoria cuando el hablante corrige su expresión (44), y cuando el hablante reformula, es decir, recapitula y vuelve a mencionar el tema sobre lo que está hablando (45):

(44) Claro, no hacer demasiado y automáticos los esquís automáticos son esas que cuando uno se da un porrazo muy fuerte el esquí salta, ¿no?, y evita que uno se rompa una pata, digo una pierna. Entonces. Sí, es estrolarse una pata es el el son es una especie de término técnico allá (CREA, Oral, BA-3, Argentina).

(45) En el año de mil ochocientos noventa y ocho, el señor Rico, diplomático muy distinguido del cual valdría la pena hacer un elogio muy extenso, porque sus opiniones en relación con la separación de Panamá constituyen la más precisa y respetable de las defensas de los intereses de Colombia, el señor Rico, digo, logró que los venezolanos aceptaran que se procediera a la ejecución integral del fallo (CREA, Oral, BO-5. Hombre de 49 años, Colombia).

Desde el punto de vista pragmático tanto digo como digo yo al final del enunciado marcan la actitud pragmática de cortesía y reserva que tiene el hablante para expresar su opinión o corregir o formular su expresión (véase también Hennemann 2016 sobre la diferencia entre creo y creo yo).

\section{OTROS CASOS}

Además de los ejemplos tratados bajo 4.1-4.3, también se han observado otros casos en los que digo aparece insertado al inicio de un enunciado, siendo precedido por otros marcadores discursivos (46-48) y otros elementos proposicionales (49). En estos casos su función parece ser de partícula cognitiva, pues su uso en el enunciado no tiene un significado concreto y si se le omite no altera el contenido proposicional. Este uso de partícula cognitiva de digo permite al hablante ganar tiempo para estructurar sus pensamientos 
y luego, expresar su enunciado. En estos casos, digo puede aparecer tanto con o sin el pronombre personal yo:

(46) Y sobre todo, yo digo, aprovecho para poner en alerta a las personas que se dedican a recepcionar y enviar fax Exacto. Porque es muy fácil, ¿no?, es muy fácil enviar un fax Cuidado con las mujerucas éstas que van y mandan faxes (CREA, Oral, Red Global: enlace global con Hildebrandt, 25/05/98, CANAL 13 TV, Peru).

(47) ¡Qué bueno!, digo, al menos la riqueza estaría mejor distribuida en este hemisferio. Pero ellos construyen una gigantesca muralla en la frontera de México con Estados Unidos para impedir la inmigración de los del sur. No hay puertas abiertas ni residencia automática para ellos (CREA, Oral, Discurso de Fidel Castro en la clausura del II Encuentro Mundial de Educación Especial, Cuba).

(48) Pero eso cuando empieza, eso empieza va apareciendo, y cuando usted se da cuenta las cosas han cambiado, pero es paulatino. Por ejemplo, digo, yo vi nacer La Florida ¡imagínese usted!, yo vi nacer San Agustín del Sur, yo vi nacer El Conde. Le digo que son muy relativamente recientes, porque yo no soy tampoco un viejecito chuchumeco que está me tengan que sacar a que coja sol. Bueno, y yo vi todo eso. [...] (CREA, Oral, CSHC-87 Entrevista 127, Venezuela).

(49) Me parece que es bien interesante. Yo para cuando estaba haciendo mi doctorado, cambié de de campo, del estudio de las culturas precolombinas a al estudio de de la historia y el arte colonial. Y el arte colonial y y y, digo, y la historia colonial del Caribe es una cosa verdaderamente interesantísima. Mire, yo le digo que es una cosa terrible (CREA, Oral, PR-4. Mujer de 29 años, Puerto Rico).

Entonces, en todos los ejemplos anteriores (46-49) yo digo y digo cumplen una función de partícula cognitiva, teniendo un efecto retroactivo hacia el locutor mismo, su uso no es indispensable en el enunciado.

Otro caso particular es la función discursiva reformulativa de digo cuando aparece precedido por el adverbio de modo como, ya sea en posición parentética o al inicio del enunciado, y usado sin (como digo) o con el pronombre personal yo, que por general siempre aparecerá pospuesto (como digo yo):

(50) Hoy día ya, si uno abusa de información, en sentido que los periodistas mismos como ya tienen posibilidades de explicar lo que está pasando y también tienen contacto directo con las bases, con los sindicatos, entonces se explayan en muchas cosas que, como digo, a veces era un abuso porque ya dan tantas cosas que Hay hay mucha sobre la cuestión (CREA, Oral, Encuesta 107, Paraguay). 
(51) Como digo, la ley debe ser amplia, y en la medida en que lo sea comprenderá ese tipo de situaciones, como asimismo las que menciona la indicación en debate. Por esta razón, reafirmando lo que la Comisión estimó en su oportunidad, a saber, que la norma era innecesaria, y que debe aplicarse la hipótesis general, voy a votar en contra de la indicación. Y creo que el Senado no puede aprobarla (CREA, Oral, Sesión 37, en miércoles 6 de marzo de 1996, Chile).

(52) [T] odo esto, puede conducir a que Chile se convierta potencialmente en un exportador de estos principios activos, lo que sería una gran entrada en dólares por concepto de exportación, y, al mismo tiempo, se está realizando una investigación de tipo aplicado, como digo yo, que es lo que Chile necesita en este momento. Ahora, ¿esas son dos posibilidades que tú tienes? (CREA, Oral, CH-2. Hombre de 27 años. Químico, Chile).

(53) Entonces, se tratan temas que se donde se haga labor, se despierten esas inquietudes y, a pesar de que uno cree que las revistas femeninas son sumamente frívolas, Laura, que es en la revista donde yo trabajo, trata, como digo yo, de de ser algo diferente (CREA, Oral, BO-4. Mujer de 32 años. Diagramadora de impresos, sección de arte, Colombia).

Si bien, en los ejemplos anteriores (50-53) como digo/ como digo yo parece cumplir una función de marcador discursivo reformulativo explicativo, por medio del cual el hablante recapitula y explica lo que ha venido diciendo, también es de uso pragmático, porque el hablante intenta atraer la atención del interlocutor hacia él, indicando que es él (como digo [yo]) que afirma ese enunciado o da su opinión al respecto porque sabe de qué está hablando (véanse todos los ejemplos anteriores 50-53 donde se encuentran elementos que explicitan el conocimiento del hablante). En este caso, también se puede decir que el uso de como digo/ como digo yo es epistémico porque marca la actitud epistémica del hablante que tiene sobre lo que dice. En el siguiente ejemplo, el uso del pronombre personal te marca que el hablante sabe de qué está hablando:

(54) Ya. Y a la vez también se les va a dar una charla por una persona especializada sobre nutrición, sicología, pediatría, qué bien. que los ayuda a ellos también a poderse desarrollar mejor dentro de su hogar, ¿no? Claro. Así que, como te digo, en est no nos da el tiempo para más, ¿ya? La preparación de materia para los chicos quisiera dedicarme a otras cosas, pero por ahora no puedo, y sobre todo que, mira, yo llego y prácticamente es atender a mis hijos, que vienen con las tareas y Claro. ahora, por ejemplo, mira, ha salido un poco tarde porque tenía que dejarla, a la menor, con todas las tareas aprendidas, ya solamente 
para escribir no más, que ya eso lo hace ya sola (CREA, Oral, LI-10. Mujer de 40 años, Perú).

Otros casos similares, donde se puede observar la actitud epistémica del hablante, son el uso de digo con determinados elementos sintácticos, como y ya le [s] digo; mire, yo le digo; ya te digo; yo te digo y le digo yo, entre otros. En los siguientes ejemplos, digo asume una función epistémica, pero marca la certeza del contenido del enunciado, porque el hablante sabe de lo que está hablando:

(55) [...] Y ya le digo, yo trabajé veintiún años allí, todavía a mí todas ellas, bueno, me escriben y me mandan felicitaciones en Navidad, y mira que hace tiempo que se fueron, que yo no las veo, y donde quiera que yo voy, hay una de ellas, ¡ave María!, se ponen tan contentas cuando me ven (CREA, Oral, PR-14. Mujer de X años, Puerto Rico).

(56) Aquél es un país muy grande, y ya les digo, violento, como regla general, violencia que se impulsa y se inspira muchas veces a través de los medios de divulgación masiva, el cine, la televisión, los juegos infantiles y otras vías. Ese país necesita paz interna y necesita realmente, más que nadie, poner bajo control y prevenir los riesgos que tiene por delante (CREA, Oral, Discurso de Fidel Castro en el acto central por el 45 aniversario del asalto a los cuarteles Moncada, Cuba).

(57) [...] Mire, yo le digo que es una cosa terrible, pero aquí en Puerto Rico no, si lo estoy usando de cenicero aquí en Puerto Rico verdaderamente, nosotros no desarrollamos un sentido de de de identificación, ni de continuidad con el resto del Caribe, lo cual es absurdo, completamente absurdo. [...] (CREA, Oral, PR-4. Mujer de 29 años, Puerto Rico).

(58) ¿En serio? Sí, como doce mil pesos. Oíme, y en literatura este el problema de la literatura también es serio porque tampoco leen, puros fragmentos. En absoluto. Ya te digo, yo leí un año mis alumnos leyeron un libro, en todo el año: Murámonos, Federico (CREA, Oral, CR-9. Mujer de 46 años. Profesora universitaria, Costa Rica).

(59) [...] Yo te digo, yo estoy maravillada por eso, pero A es otro Así hay otro aquí, que es casi un problema ahorita. Le dije a la madre: bueno, tú verás qué haces, porque es increíble: se monta en los cerros y es yo no sé, una cantidad de personajes que yo no conozco, pues, yo no he podido ponerme a ver los programas (CREA, Oral, Muestra IX, encuesta 2M-165-i, Venezuela). 
(60) El paisaje de Chile es muy lindo. Una anécdota es que yo le contaba al a uno de los compañeros de allá, al anfitrión, ¿verdad?, al de Chile pensé que en mi país no hay montañas, le digo yo. No puede ser, me dice él, porque allá del lado que mires vos ves una montañita así (CREA, Oral, Encuesta 105, Perla Margarita López Mesa, Paraguay).

\section{RESULTADOS, CONCLUSIONES Y PERSPECTIVAS}

De acuerdo a su posición sintáctica -ya sea al inicio, a la mitad o al final del enunciado- el significado procedimental no canónico de digo varía, sobre todo, cuando aparece con el pronombre personal yo ante y pospuesto (yo digo y digo yo).

En posición prospectiva, al inicio del enunciado, yo digo y digo suelen aparecer entre comas y con otros marcadores discursivos, los cuales marcan la posición argumentativa del hablante (de hecho, yo digo), así como la conclusión del hablante (entonces, yo digo; por ello, digo y por eso digo). En tales casos, digo y yo digo asumen la función de un marcador argumentativo y conclusivo respectivamente y refuerzan el valor de verdad del enunciado. También se encontraron casos en los que yo digo aparece antepuesto por la conjunción $y$, indicando que el hablante es el autor de tal información. En este último caso, su función es discursiva-evidencial. No obstante, en el caso de digo con el pronombre yo pospuesto (digo yo), digo yo aparece antecedido por la conjunción $y$-por medio del cual el hablante expresa su opinión- y se atenúa el contenido de su enunciado.

En posición parentética, insertada en medio del enunciado entre comas, solo se encontraron casos de digo y digo yo (solo con el pronombre yo pospuesto), por medio de los cuales se marca la incertidumbre u opinión del hablante, es decir, la actitud epistémica del hablante. Digo y digo yo se comportan como marcadores epistémicos, atenuando el valor de certeza del enunciado. Además, en los casos analizados, digo y digo yo aparecen en contextos modalizados, es decir, con elementos epistémicos que explicitan la incertidumbre, duda o inseguridad del hablante sobre lo que dice. Desde el punto de vista pragmático, digo y digo yo en posición parentética se usa como un marcador de cortesía, por medio del cual el hablante parece expresar su opinión en forma cautelosa y prudente.

En posición retrospectiva, al final del enunciado, se encontraron solo casos de digo y digo yo precedidos por una coma, cerrando una proposición 
o modalizando el grupo proposicional a su izquierda. En ambos casos se atenúa el contenido del enunciado porque el hablante expresa su opinión al respecto. También se encontraron casos en los que digo asume la función de un marcador reformulativo o correctivo, es decir, recapitula o corrige su enunciado anterior. Entonces, se puede decir que digo y digo yo al final del enunciado cumplen no solo una función discursiva, sino también epistémica y pragmática de cortesía.

También se encontraron casos en los que digo/ yo digo asume la función de una partícula cognitiva, usada por el hablante para ganar tiempo y poder estructurar mejor su enunciado (cf. ejemplos 46-49).

Indudablemente, el rasgo composicional es también un factor muy importante para la interpretación procedimental de digo. Cuando digo aparece con el pronombre personal yo antepuesto (yo digo) se enfatiza y se subraya más el autor yo que dice u opina sobre algo. Pero cuando se usa el pronombre yo pospuesto (digo yo), la marca del autor yo -que opina, piensa o cree sobre algo- queda en segundo plano y se obtiene una lectura modal epistémica que indica la menos confiabilidad que tiene el hablante sobre lo que dice.

En suma, si bien el significado procedimental de digo varía de acuerdo a su posición sintáctica y función composicional, es decir, si va acompañado del pronombre personal yo en forma antepuesta o pospuesta, también hay que tener en cuenta si aparece separado por una coma (o por comas) o si le acompañan otros elementos proposicionales que pueden contribuir con su significado discursivo, pragmático, epistémico y de partícula cognitiva.

Este tema también podría estudiarse desde el punto de vista diatópico y observar si en algunos casos (usos sintácticos de digo con la presencia o no del pronombre yo) se trata de una variedad del español estándar, sobre todo, del español americano y analizar si tales usos, como por ejemplo, digo yo al final del enunciado son estructuras fijas o motivadas por el contexto sintáctico o enunciativo. Asimismo, se puede realizar un estudio contrastivo del uso procedimental de digo, digo yo y yo digo en otras lenguas no romances, por ejemplo, en el inglés o el alemán y buscar posibles correspondencias con el verbo decir en tales lenguas en primera persona, por ejemplo, I say/ 'say en inglés e ich sage/ sage ich en alemán, o comprobar si existen otras formas, desde el punto de vista contrastivo, para traducir [yo] digo [yo]. De este modo, se podría comprobar qué factores pueden motivar los diversos usos procedimentales de digo en otras lenguas que no sea el español. 


\section{REFERENCIAS BIBLIOGRÁFICAS}

Bezuidenhout, Anne. 2004. Procedural Meaning and the Semantics/Pragmatics Inferface. En Claudia Bianchi (coord.), The Semantics/Pragmatics Distinction, pp. 101-131. Stanford: CSLI Publications.

Blakemore, Diane. 1987. Semantic Constraints on Relevance. Oxford: Oxford University Press.

2004. Relevance and Linguistic meaning. The Semantics and Pragmatics of Discourse Markers. Cambridge: Cambridge University Press.

Cappelli, Gloria. 2007. "I reckon I know how Leonardo da Vinci must have felt...". Epistemicity, evidentiality and English verbs of cognitive attitude. Pari: Pari Publishing.

Carston, RoByn. 2002. Thoughts and Utterances. The Pragmatics of Explicit Communication. Cornwall: Blackwell Publishing.

Cornillie, Bert. 2010. On conceptual semantics and discourse functions: The case of Spanish modal adverbs in informal conversation. Review of Cognitive Linguistics 8 (2): 300-320.

CORPUS DEL ESPAÑOL (CDE). http://www.corpusdelespanol.org/.

CORPUS DE LA REAL ACADEMIA ESPAÑOLA (CREA). http://corpus.rae.es/creanet.html.

Díaz, YaRUBi y María LABARCA. 2010. Las formas digo, vamos a decir, dicen, como marcadores discursivos (intensificadores, atenuadores y justificadores) en el habla de Mérida, Venezuela. Lengua y Habla 14: 12-24.

Domínguez, Carmen y Elsa Mora. 1995. Corpus Sociolingüístico de Mérida. Mérida: Universidad de Los Andes, Grupo de Lingüística Hispana.

FANT, LARS. 2005. Discourse perspectives on modalisation: the case of accounts in semistructured interviews. En Alex Klinge y Henrik Høeg Müller (coord.), Modality: Studies in Form and Function, pp. 103-121. Equinox: London.

2006. La modalización del acierto formulativo en conversaciones argentinas y chilenas. Estocolmo: Universidad de Estocolmo.

FernándeZ, Cristina. 2002. Funciones y usos del marcador discursivo digo. En Alberto Bernabé, José Antonio Berenguer Sánchez, Margarita Cantarero y José Carlos de Torres Martínez (coord.), Presente y Futuro de la Lingüística en España. Actas del II Congreso de la Sociedad Española de Lingüistica. La sociedad lingüistica 30 años después, pp. 541-548. Madrid: S.E.L.

Fuentes, Catalina. 2004. Enunciación, aserción y modalidad. Tres clásicos. AEF XXVII: 121-145.

Hassler, Gerda. 2010. Epistemic modality and evidentiality and their determination on a deictic basis. En Martin G. Becker y Eva-Maria Remberger (coord.), Modality and Mood in Romance. Modal Interpretation, Mood Selection, and Mood Alternation, pp. 95-108. Berlin: De Gruyter.

Hennemann, Anja. 2016. A cognitive-constructionist approach to Spanish creo Ø and creo yo '[I] think'. Folia Linguistica 50 (2): 449-474.

Huang, Yan. 2007. Pragmatics. Oxford: Oxford University Press.

Ifantidou, Elly. 2001. Evidentials and Relevance. Amsterdam: John Benjamins.

Martín Zorraquino, María A. y José Portolés. 1999. Los marcadores del discurso. En Ignacio Bosque y Violeta Demonte (coord.), Gramática descriptiva de la lengua española, pp. 4051-4207. Madrid: Espasa Calpe.

Meyer-Hermann, Reinhard. 1988. Atenuación e intensificación (Análisis pragmático de sus formas y funciones en español). Anuario de estudios filológicos 11: 275-290. 
Nogueira da Silva, Antonio Messias. 2010. Las teorías pragmáticas y los marcadores del discurso. Letra Magna 13 [en línea]. Disponible en http://www.letramagna.com/ Artigo11_13.pdf [Consulta 03/10/2017].

PoRTolÉs, José. 1998. Marcadores del discurso. Barcelona: Ariel.

Quero, Salvador. 2014. Caracterización pragmática de la expresión gramaticalizada ya te digo: su valor en estrategias conversacionales. Oralia 17: 267-287.

Simon-Vandenbergen, Anne-Marie y Karin Aijmer. 2007. The Semantic Field of Modal Certainty. A Corpus-Based Study of English Adverbs. Berlin/ New York: Mouton de Gruyter.

Sorensen, Helga. 1999. El verbo decir como marcador de discurso en el habla de Caracas. En José Antonio Samper y Magnolia Troya (coord.), Actas del IX Congreso Internacional de la Asociación de Lingüistica y Filología de la América Latina. Las Palmas de Gran Canaria del 22 al 27 de 1996, pp. 1273-1282. Las Palmas de Gran Canaria: Librería Nogal.

Sperber, Dan y Deirdre Wilson. ${ }^{2} 1995$ [1986]. Relevance: Communication and Cognition. Cambridge/ Massachusetts: Harvard University Press.

1998. The mapping between the mental and the public lexicon. En Peter Carruthers y Jill Boucher (coord.), Language and Thought: Interdisciplinary Themes, pp. 184-200. Cambridge: Cambridge University Press.

Wilson, Deirdre y Dan Sperber. 1993. Linguistic form and relevance. Lingua 90 (1/2): 1-25. 